\title{
On the need for bias correction in regional climate scenarios to assess climate change impacts on river runoff
}

\author{
M. J. Muerth ${ }^{1}$, B. Gauvin St-Denis ${ }^{2}$, S. Ricard ${ }^{3}$, J. A. Velázquez ${ }^{2}$, J. Schmid ${ }^{1}$, M. Minville ${ }^{4}$, D. Caya ${ }^{2}$, D. Chaumont ${ }^{2}$, \\ R. Ludwig ${ }^{1}$, and R. Turcotte ${ }^{3}$ \\ ${ }^{1}$ Department of Geography, University of Munich (LMU), Munich, Germany \\ ${ }^{2}$ Consortium Ouranos, Montréal, QC, Canada \\ ${ }^{3}$ Centre d'expertise hydrique du Québec (CEHQ), Québec City, QC, Canada \\ ${ }^{4}$ Institut de recherche d'Hydro-Québec (IREQ), Varennes, QC, Canada
}

Correspondence to: M. J. Muerth (m.muerth@1mu.de)

Received: 15 August 2012 - Published in Hydrol. Earth Syst. Sci. Discuss.: 7 September 2012

Revised: 23 January 2013 - Accepted: 1 February 2013 - Published: 19 March 2013

\begin{abstract}
In climate change impact research, the assessment of future river runoff as well as the catchment-scale water balance is impeded by different sources of modeling uncertainty. Some research has already been done in order to quantify the uncertainty of climate projections originating from the climate models and the downscaling techniques, as well as from the internal variability evaluated from climate model member ensembles. Yet, the use of hydrological models adds another layer of uncertainty. Within the QBic3 project (Québec-Bavarian International Collaboration on Climate Change), the relative contributions to the overall uncertainty from the whole model chain (from global climate models to water management models) are investigated using an ensemble of multiple climate and hydrological models.

Although there are many options to downscale global climate projections to the regional scale, recent impact studies tend to use regional climate models (RCMs). One reason for that is that the physical coherence between atmospheric and land-surface variables is preserved. The coherence between temperature and precipitation is of particular interest in hydrology. However, the regional climate model outputs often are biased compared to the observed climatology of a given region. Therefore, biases in those outputs are often corrected to facilitate the reproduction of historic runoff conditions when used in hydrological models, even if those corrections alter the relationship between temperature and precipitation. So, as bias correction may affect the consistency between RCM output variables, the use of correction techniques and
\end{abstract}

even the use of (biased) climate model data itself is sometimes disputed among scientists. For these reasons, the effect of bias correction on simulated runoff regimes and the relative change in selected runoff indicators is explored. If it affects the conclusion of climate change analysis in hydrology, we should consider it as a source of uncertainty. If not, the application of bias correction methods is either unnecessary to obtain the change signal in hydro-climatic projections, or safe to use for the production of present and future river runoff scenarios as it does not alter the change signal.

The results of the present paper highlight the analysis of daily runoff simulated with four different hydrological models in two natural-flow catchments, driven by different regional climate models for a reference and a future period. As expected, bias correction of climate model outputs is important for the reproduction of the runoff regime of the past, regardless of the hydrological model used. Then again, its impact on the relative change of flow indicators between reference and future periods is weak for most indicators, with the exception of the timing of the spring flood peak. Still, our results indicate that the impact of bias correction on runoff indicators increases with bias in the climate simulations.

\section{Introduction}

In the recent past, the availability of regional climate model (RCM) simulations, especially over Europe and North America, has considerably increased, while also the understanding 
about the uncertainties related to regional climate simulations has been improved based on model ensembles (e.g., by the PRUDENCE project (Déqué et al., 2007)). At the same time, the assessment of climate change impacts on the hydrological cycle based on projections of global climate models (GCMs) dynamically downscaled by RCM nesting has been a major research effort, especially in the past decade (Bergstrom et al., 2001; Horton et al., 2006; Graham et al., 2007; Andersson et al., 2011). Although most RCMs include descriptions of surface and subsurface runoff processes, biases in precipitation and moisture fluxes generally result in weak agreement between RCM runoff and observations (Hagemann et al., 2004; van den Hurk et al., 2005). Therefore, most studies have used a model chain consisting of a combination of $\mathrm{GCM}(\mathrm{s})$ and $\mathrm{RCM}(\mathrm{s})$, various methods to correct biases and a hydrological model (HyM) to project potential future changes in water resources and runoff, as summarized in Teutschbein and Seibert (2010).

Climate science has increased our understanding of the climate system considerably, yet the uncertainty of projections of regional climate changes is still large and thus should be recognized and accounted for especially in impact and adaptation studies (Foley, 2010). Besides the uncertainties due to imperfect climate models (process descriptions, parameters and boundary conditions), there is considerable uncertainty about future greenhouse gas emissions and the natural variability of the climate system (Foley, 2010). An estimate of the latter source is created by varying the initial conditions of the GCM that forces a particular RCM, so the results of each of these GCM-RCM members span the range of internal variability of a particular GCM-RCM combination, as reported for example in de Elía and Côté (2010). Then again, the uncertainty of the emissions scenarios seems to be not that important for global warming until the late 21st century and beyond (Hawkins and Sutton, 2009).

A few studies have already compared the impact of these different sources of uncertainty on the hydrological response of regional-scale catchments or on the variables most important for hydrological models, precipitation and temperature. Déqué et al. (2007) compared the effects of different sources of uncertainty, including the emissions scenario, the choice of GCM and RCM, and varied initial conditions on seasonal precipitation and temperature over Europe. They found that the uncertainty arising from different GCMs is generally the largest, while the choice of RCM strongly affected summer precipitation and the choice of emissions scenario had a significant effect only on summer temperatures. Horton et al. (2006) used a similar set of climate model simulations for a hydrological impact study over the Swiss Alps and found that the uncertainty introduced by the choice of RCM is not explicitly deductible from the climatic ensembles; hence it is assumed to be on the order of the GCM uncertainty. Graham et al. (2007) found that the choice of GCM is more important than the emissions scenario or the RCM used in their multicatchment study on future (2071-2100) hydrological change.
The assessment of the uncertainty components in water related variables for climate change projections showed that the climate system internal variability is a major player for impact studies at the watershed scale (Music and Caya, 2007, 2009; Braun et al., 2011).

The projection of potential climate change impacts on intensely used watersheds and the development of adaptation options are major challenges in water resource management. Within the Québec-Bavarian International Collaboration on Climate Change $\left(\mathrm{QBIC}^{3}\right)$ project, four regional-scale catchments strongly affected by different types of hydraulic infrastructure (dams, reservoirs, water transfer systems) are investigated. Because the uncertainty connected to any projection of climate change impacts on runoff characteristics has to be quantified, a modeling chain of both multiple climate scenarios and hydrological models is employed. The general aim of the projections for the Bavarian and Québécois catchments is to investigate the long-term changes in the annual runoff regime and the average change in high- and low-flow characteristics during different seasons. The projected changes are then fed into water management models to simulate the effects of these changes on the water infrastructure and to investigate potential adaptation options.

Since the ensemble of hydrological models includes both simple, lumped as well as more complex, distributed models, physically consistent and spatially distributed meteorological inputs are needed for runoff projection. Furthermore, additional variables besides temperature and precipitation (e.g., humidity and global radiation) at the sub-daily timescale are needed. Following the findings summarized in Maraun et al. (2010), dynamical downscaling of global climate projections is an adequate approach to fulfill these needs. Although there are other options in the wide field of statistical downscaling methods, the use of RCM data furthermore offers the advantage that it preserves the physical coherence between atmospheric variables, especially between precipitation and temperature (Fowler et al., 2007).

Yet, as the spatial resolution of distributed hydrological models usually applied on managed watersheds is distinctly finer than that of typical RCM applications, further downscaling is required if regional- to local-scale patterns are to be resolved by the impact models (Maraun et al., 2010). Especially in terrain with steep gradients, the distribution of RCM outputs to the impact model scale based on elevation can improve hydrological modeling results compared to raw RCM outputs as shown by Wilby et al. (2000).

Still, RCM data may contain biases that prevent an appropriate reproduction of the historic (observed) hydrological conditions from simulations (which is the "minimum standard" as stated in Wood et al. (2004) for a "useful" downscaling technique). Therefore, in most cases some form of bias correction is necessary, especially for precipitation (Maraun et al., 2010) but also for temperature. The correction of other climate model variables (radiation, wind and humidity) seems to have less impact on hydrological climate 
change projections (Haddeland et al., 2012). A full integration of both downscaling and bias correction is reported in Kleinn et al. (2005), who constructed a model chain for the large Rhine basin upstream of Cologne $\left(145000 \mathrm{~km}^{2}\right)$ by forcing the distributed hydrological model WASIM with bias-corrected RCM fields. To account for fine-scale heterogeneities in complex terrain, they used a model interface that superimposes stationary, topography-induced patterns of the hydrological model scale on the coarse-scale RCM temperature and precipitation fields.

Bias corrections of RCM outputs typically make use of one of two general approaches: extracting deltas (differences between a future and a reference period) to be applied on observed meteorological data in order to construct future time series, or deriving scaling parameters to adjust both past and future RCM outputs to more closely fit observed climatic conditions (Teutschbein and Seibert, 2010). Different variations of those are summarized in Déqué (2007). Fowler et al. (2007) state that the physical coherence between temperature and precipitation is largely preserved in bias-corrected RCM data, although this certainly depends on the methods used for those variables. Furthermore, bias correction can affect the absolute and/or the relative temporal change of a meteorological variable. For example, Graham et al. (2007) have shown that the delta method preserves the average change in precipitation from the RCM data, while a scaling of precipitation intensity better preserves the changes in variability. So in summary, bias correction of RCM simulations does not guarantee physical consistency and may affect the climate change signal to some extent. Hagemann et al. (2011) report that bias correction of GCM data may affect the hydrological climate change signal in specific locations and seasons. Hence the use of bias correction techniques in hydrology to adjust GCM or RCM data is disputed, as discussed by Ehret et al. (2012). So the question we try to address in this paper is: Is it really necessary to correct biases to assess climate change impacts, if uncorrected RCM data does not reproduce observed conditions very well?

For this purpose, we investigate the impact of bias correction of precipitation and near-surface air temperature on the simulations from four different hydrological models in two natural flow catchments in southern Germany and southern Québec when driven by multiple GCM-RCM data sets for both a reference (1971-2000) and a future period (20412070). Precipitation is corrected by the local intensity scaling (LOCI) method of Schmidli et al. (2006), while air temperature is modified by monthly additive correction. The methods were selected for their simplicity and have some inherent flaws: The monthly correction may create jumps in the corrected data sets between months, and following Themeßl et al. (2011) LOCI performance is slightly inferior to the quantile mapping approach, especially at high precipitation intensities. River runoff is simulated both with direct and biascorrected meteorological drivers produced by RCMs. From the simulated daily runoff, hydrological indicators character- izing mean, high and low flows as well as the timing of the spring flood are computed. Based on those results, three main questions are raised:

1. Does bias correction provide a more consistent representation of river runoff for the past? This first analysis compares the deviation of the simulated runoff regimes and hydrological indicators from observed values over the reference period. It assesses the capacity of a hydro-climatic simulation ensemble to provide a consistent representation of the river runoff regime.

2. What are the expected impacts of climate change on the river runoff regime? The second analysis explores the trends and signals provided by hydro-climatic simulation ensemble over Québec and Bavaria. The results of the model chain with and without bias correction are analyzed regarding the relative change of hydrological indicators for the future time period.

3. Does bias correction affect the estimation of future change in hydrological indicators? Then, the effect of bias correction on the projected change signal and thus its contribution to the overall uncertainty, also in relation to the actual biases of the regional climate simulations, is explored. This evaluates the relevance of applying time consuming bias correction methods in the scope of hydrological climate change impact assessment.

\section{Data and methods}

\subsection{The investigated catchments}

The two catchments investigated in this study, the au Saumon and the Loisach River, are both natural flow tributaries of larger, heavily managed watersheds located in southern Québec (Canada) and southern Bavaria (Germany), respectively. The au Saumon River at gauge "Saumon" has a catchment area of $738 \mathrm{~km}^{2}$, while the Loisach River at gauge "Schlehdorf" has an area of $640 \mathrm{~km}^{2}$. Thus, both are relatively small for climate change modeling studies, and their mountainous character with a strong relief and raw soils mainly covered by forests leads to distinct runoff regimes. As stated before, both are important tributaries for two larger river systems, the Haut-Saint-François in Québec $\left(2922 \mathrm{~km}^{2}\right)$ and the Upper Isar in southern Bavaria $\left(2814 \mathrm{~km}^{2}\right)$ (as depicted in Fig. 1). Yet, these larger systems are highly regulated by dams, reservoirs and water transfer systems, so climate change impact on river runoff cannot be easily quantified without taking water management into account.

The au Saumon catchment topography is moderately steep, with elevation ranging from $1100 \mathrm{~m}$ at Mont Mégantic to $270 \mathrm{~m}$ at the catchment outlet. Land cover is dominated 

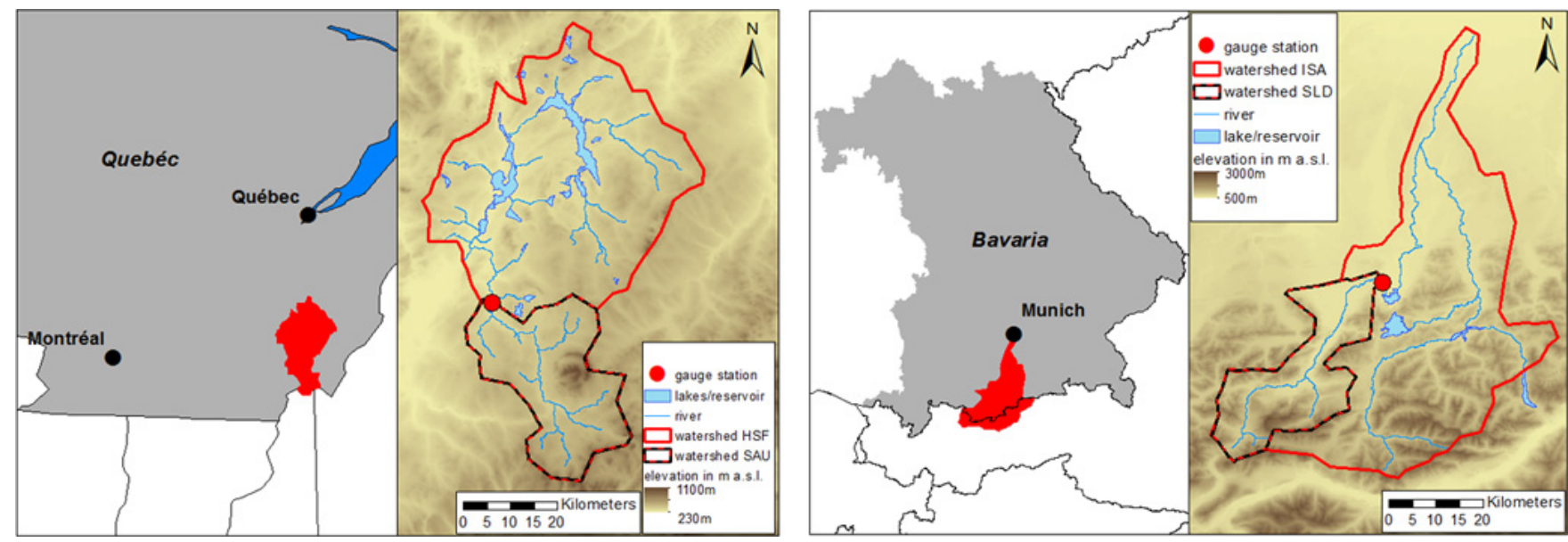

Fig. 1. Location and relief of the Haut-Saint-François (HSF, left) and the Upper Isar (ISA, right) watersheds including the drainage divide of the investigated head catchments of gauges Saumon (SAU) and Schlehdorf (SLD) from Velázquez et al. (2013).

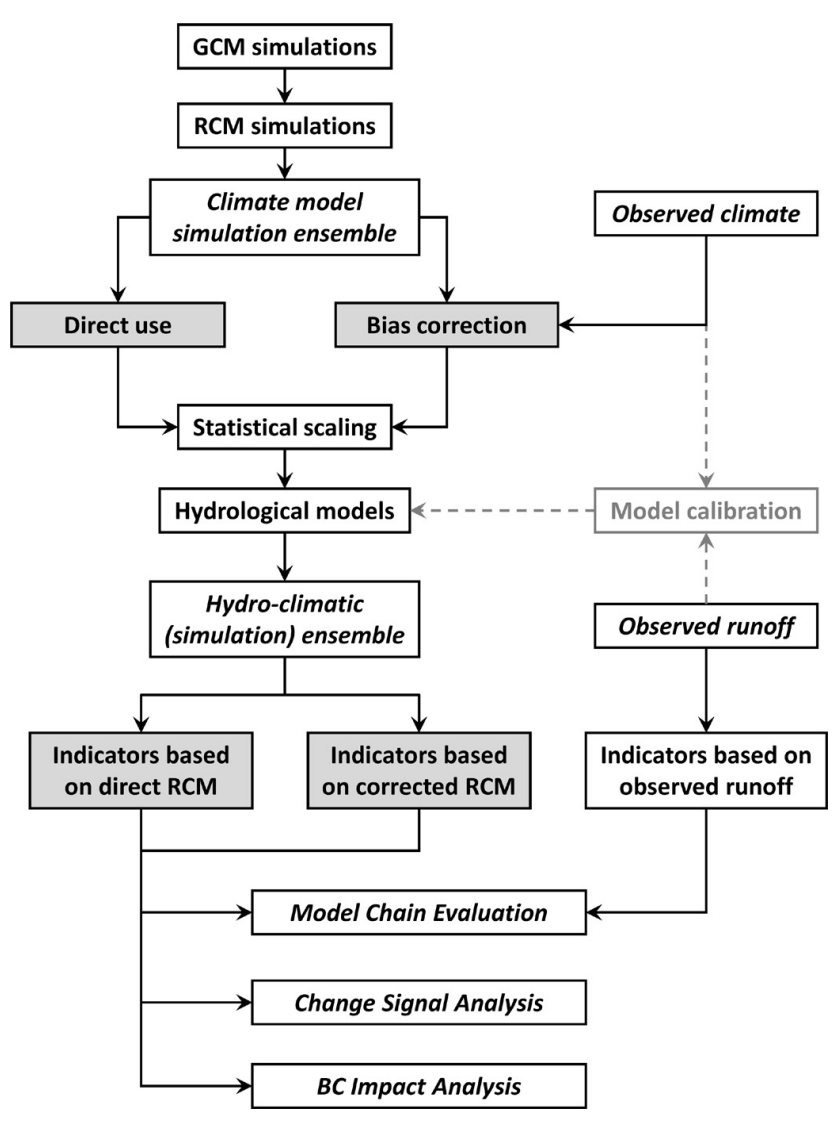

Fig. 2. Workflow of the hydro-climatic ensemble scheme used to investigate the impact of bias correction on simulated runoff regimes. Dashed arrows illustrate the model calibration done in advance of the impact analysis.

by deciduous forest that grows on silt loam soils overlying the Appalachian bedrock. The annual overall mean flow at the outlet is $18 \mathrm{~m}^{3} \mathrm{~s}^{-1}$, yet the nivo-pluvial runoff regime is dominated by a large snow-melt peak in spring $\left(54 \mathrm{~m}^{3} \mathrm{~s}^{-1}\right.$ in April). Although precipitation in summer is slightly higher than in winter, only intense convective precipitation events can create low magnitude summer floods. In general, flows are low in summer due to high evaporation and occasional dry spells $\left(10 \mathrm{~m}^{3} \mathrm{~s}^{-1}\right.$ in August) and also in winter due to low temperatures and a long-lasting snow cover.

Most of the Loisach catchment upstream of gauge Schlehdorf is located in the Bavarian Limestone Alps; therefore, the relief is steep with elevations ranging from $2962 \mathrm{~m}$ at the Zugspitze to $600 \mathrm{~m}$ at the catchment outlet. Land use is dominated by coniferous forests with small parts of marshland, pasture and rocky outcrops. Raw soils on limestone are common in the mountains, while in the low-lying parts loamy soils with parts of gravel are found. The glacial runoff regime of the Loisach is controlled by snowmelt in late spring and precipitation events in summer. Mean annual runoff is $22 \mathrm{~m}^{3} \mathrm{~s}^{-1}$, with a minimum in winter and a maximum in spring and early summer when the snowmelt in the mountains gives way to the precipitation maximum in summer.

\subsection{The hydro-climatic model chain}

The QBic3 project investigates the impact of climate change on water resources with a focus on the model-related uncertainties regarding the future changes in runoff regime. To do so, a hydro-climatic model chain has been constructed (as illustrated in Fig. 2) linking regional climate models with hydrological models. The quantification of uncertainties in the model chain requires the use of ensembles. Typically, the uncertainties and potential errors in RCM simulations are related to emission scenarios, climate model structure and parameterization, but also the natural variability of climate (Foley, 2010). So, similar to other investigations (as summarized for example in Teutschbein and Seibert, 2010) the climate model simulation ensembles are produced from 
different simulations of global and regional climate models for both catchments (see Sect. 2.3). As RCM simulations are usually biased when compared to observations, the two main drivers for hydrological models (HyMs), precipitation and temperature, are corrected to better fit the observed climatology. Other atmospheric forcings are not corrected due to a sparse database in the investigated regions, although they are used in some HyMs. Finally, all RCM fields are downscaled for the distributed hydrological models using the statistical scaling tool SCALMET (Marke, 2008), which conserves mass and energy at the RCM scale. This dualistic approach regarding bias correction and downscaling of RCM outputs is followed in order to separately estimate the impact of bias correction on HyM results without having to account for changes in spatial distribution of these variables.

Besides the climate model uncertainties, an ensemble of hydrological models of different complexity is required as well to reflect the predictive uncertainties of hydrological modeling (see Velázquez et al., 2013). Hence, a so-called "hydro-climatic simulation ensemble" of simulated runoff time series for both a reference (1971-2000) and a future period (2041-2070) is produced by feeding different hydrological models with a suite of climate simulations. The chosen ensemble of hydrological models (see Sect. 2.4) reflects different levels of model complexity and assesses the uncertainty related to model structure (i.e., the uncertainty related to the internal computation of hydrological processes). All HyMs are calibrated or optimized using observed climate station data to clearly reflect the impact of climate model biases on simulated runoff. From those daily runoff time series, four hydrological indicators (HI) are calculated:

1. Mean flow over the whole period (MF): mean of all daily values in $\mathrm{m}^{3} \mathrm{~s}^{-1}$ over a given period; this indicator mainly reflects the annual water balance of a catchment.

\section{7-day duration low flow with a 2-year return period} (7LF2): a (seasonal) indicator of long-term low flow sustained over a period of 7 days. It is computed using a 7-day moving average of runoff from which the 2-year return period of its minimum yearly values assuming a Pearson III distribution is analyzed (DVWK, 1983).

3. High flow with a 2-year return period (HF2): the flood peak, which statistically occurs every two years is based on seasonal (summer, winter) maximum daily runoff values; again a Pearson III-type distribution is assumed (DVWK, 1979).

4. Julian day of the spring flood half-volume (JDSF): Julian day at which half of the total volume of water for the spring flood period has been discharged at a gauge; applied to the months February till June for Québec and March till July for Bavaria.

7LF2 and HF2 can be evaluated over the summer (SUM) or winter (WIN) season. Because of the distinction between both runoff regimes, the summer period is fixed from June to November for the Québec site (winter from December to May) and from March to August for the Bavarian Alpine site (winter from September to February).

In the end, the "hydro-climatic simulation ensemble" is synthesized by a number of indicators related to directly used (BC0) or bias corrected (BC1) outputs of the RCMs over both the reference and future periods. To evaluate the performance of the hydro-climatic model chain, simulated average annual hydrographs are compared to the observed runoff regime. Furthermore, the relative errors $(E)$ of hydrological indicators simulated for the reference period $\left(\mathrm{HI}_{\mathrm{Ref}}\right)$ are compared to those computed from observed flow $\left(\mathrm{HI}_{\mathrm{Obs}}\right)$ :

$E=\frac{\left(\mathrm{HI}_{\mathrm{Ref}}-\mathrm{HI}_{\mathrm{Obs}}\right)}{\mathrm{HI}_{\mathrm{Obs}}}$.

The expected impacts of climate change on hydrological indicators is based on the quantification of the change signal (CS), i.e., the relative differences between indicator values calculated over reference (Ref) and future (Fut) periods:

$\mathrm{CS}=\frac{\left(\mathrm{HI}_{\mathrm{Fut}}-\mathrm{HI}_{\mathrm{Ref}}\right)}{\mathrm{HI}_{\mathrm{Ref}}}$.

At last, the rank-sum (Wilcoxon, 1945) test is used in order to compare pairs of (hydrological) change signal ensembles obtained with either direct or bias corrected RCM drivers. For each hydrological indicator, we evaluate if the two samples (BC0 and $\mathrm{BC} 1$ ) have been drawn from the same distribution (the null hypothesis) within different rejection levels. Commonly, the $5 \%$ level is used, but in this study other additional significance levels were also chosen to get a gradual estimate of sample similarity. If the test is not rejected, both distributions should provide the same information, and thus bias correction of precipitation and temperature should not be necessary to evaluate a given change signal.

\subsection{The climate data ensemble}

The choice of climate simulations for a research project is often not only determined by the scientific questions raised, but also by the availability of data and the capacity to process it within the scope of the project. The final list that was agreed upon in QBic3 is presented in Table 1. The regional climate models are the Canadian Regional Climate Model CRCM4 (de Elía and Côté, 2010; Caya and Laprise, 1999), the KNMI regional atmospheric climate model (RACMO2) (van Meijgaard, 2008) and the Rossby Centre's regional atmosphereland climate model (RCA3) (Samuelsson et al., 2011; Kjellström et al., 2011). Driving data for those models are outputs of the global climate models CGCM3, ECHAM5, HadCM3 and BCM. When multiple members are mentioned, they correspond to multiple runs of the driving models. A consequence of this particular choice of climate simulations is that natural variability will be better assessed over Québec (given that 5 members are available) while the uncertainty related 
Table 1. Number of RCM simulations available per investigated region based on IPCC emissions scenario, horizontal resolution and pilot GCM.

\begin{tabular}{lccccc}
\hline RCM & CRCM4.2.3 & RACMO2 & \multicolumn{3}{c}{ RCA3 } \\
\hline SRES & A2 & A1B & A2 & A1B & A1B \\
Resolution & $45 \mathrm{~km}$ & $50 \mathrm{~km}$ & $50 \mathrm{~km}$ & $50 \mathrm{~km}$ & $50 \mathrm{~km}$ \\
Pilot GCM & CGCM3 & ECHAM5 & ECHAM5 & HadCM3 & BCM \\
Québec runs & 5 & - & - & - & - \\
Bavaria runs & 1 & 3 & 1 & 1 & 1 \\
\hline
\end{tabular}

to the choice of regional climate models and their pilots will only be exposed over Bavaria. It has to be noted that the uncertainty introduced by greenhouse gas emissions scenarios is not accounted for over Québec and is not well represented over Bavaria, however the spread between different IPCC emissions scenarios is rather small at the chosen future time frame 2041-2070 (Hawkins and Sutton, 2009; Graham et al., 2007).

The preparation of climate model data sets as an input for catchment-scale hydrological models is accomplished by a two-step approach of correcting climate model biases if needed at the RCM grid scale before scaling the outputs to the hydrological scale of $1 \times 1 \mathrm{~km}^{2}$. As the spatial resolution of common RCM applications is about $50 \mathrm{~km}$, a model output statistics (MOS) algorithm had to be chosen to disaggregate RCM outputs to the hydrological model scale of $1 \times 1 \mathrm{~km}^{2}$. Since the aim of this further downscaling is to reproduce the typical spatial patterns of various meteorological variables in regions with (potentially) sparse meteorological station data, the chosen MOS approach SCALMET (Marke, 2008) takes advantage of three relations: (a) elevation dependencies already existent in RCM air temperature and humidity fields, (b) physical relationships between incoming radiation components and wind speeds and topography, and (c) empirical monthly elevation gradients, in our case for precipitation (Liston and Elder, 2006). Ultimately, a major advantage of SCALMET is that it conserves energy and mass at the spatial scale of the RCM grid boxes during each time step. Furthermore, Zabel et al. (2012) successfully used SCALMET to interactively couple a RCM with the hydrological land surface model PROMET, which is also used in this study.

To evaluate the main biases of the chosen RCM runs, simulated and downscaled average monthly air temperature and precipitation for both main catchments are compared to interpolated observations in Fig. 3. The observation data used to compute the reference climatology are the same that were used for calibration and validation of hydrological models over their respective basins. For the Bavarian region, this is the 1-km gridded data set from the GLOWA-Danube project interpolated with PROMET (Mauser and Bach, 2009), while for southern Québec, CEHQ provided their gridded $0.1^{\circ}$ resolution observation data sets. In the Haut-Saint-François re- gion, all members of CRCM have a distinct cold bias of the order of $2-4{ }^{\circ} \mathrm{C}$, most accentuated in late winter and early spring. This cold bias is also present at a much larger scale in the corresponding CGCM simulations (not shown). In terms of mean precipitation, there is a clear underestimation in winter and overestimation in the summer months. These biases are larger than the variation between the CRCM-CGCM members, which is a first order estimate of the natural variability for this region (less than $1^{\circ} \mathrm{C}$ and 5-10 mm month ${ }^{-1}$ ). For the Upper Isar region, RCA driven by BCM shows a $2{ }^{\circ} \mathrm{C}$ warm bias for summer, while all other RCA and RACMO simulations have biases of less than $1^{\circ} \mathrm{C}$ year round. Once again, the $\mathrm{CRCM}$ driven by $\mathrm{CGCM}$ reveals a large cold bias of about $-5^{\circ} \mathrm{C}$. The precipitation amounts of the RCA and RACMO simulations, regardless of driving GCMs, overestimate precipitation in winter and underestimate it in summer, while the CRCM shows a severe underestimation.

With these, to some extent large, biases in RCM outputs, the hydro-climatic model chain is obviously not able to plausibly reproduce observed runoff without any correction of climate model biases, as outlined in, for example, Wood et al. (2004). There are however drawbacks to bias correction (Ehret et al., 2012): (a) As it is statistical in nature, some physical coherence is sacrificed during the process. (b) An arguable assumption is made that the correction parameters derived from past data sets still hold for future time periods. (c) Part of the deviation between observed and simulated climatologies could actually be climate inherent uncertainty. In order to separate the impact of bias correction from the downscaling procedure, a monthly correction is performed at the RCM grid point scale on air temperature by subtracting the 30-year mean monthly biases. Since the biases in temperature vary only weakly between months (Fig. 3), the discontinuity introduced in the corrected data is very small. For precipitation the local intensity scaling method (LOCI) of Schmidli et al. (2006) is used, which adjusts 30-year average monthly wet-day frequency and intensity (with a wetday precipitation threshold of $1 \mathrm{~mm}$ ) and was already applied to CRCM data sets by Minville et al. (2009) and Chen et al. (2011). Since the LOCI method was developed for daily data, the resulting daily precipitation is redistributed to the sub-daily timescale proportionally to the original RCM 

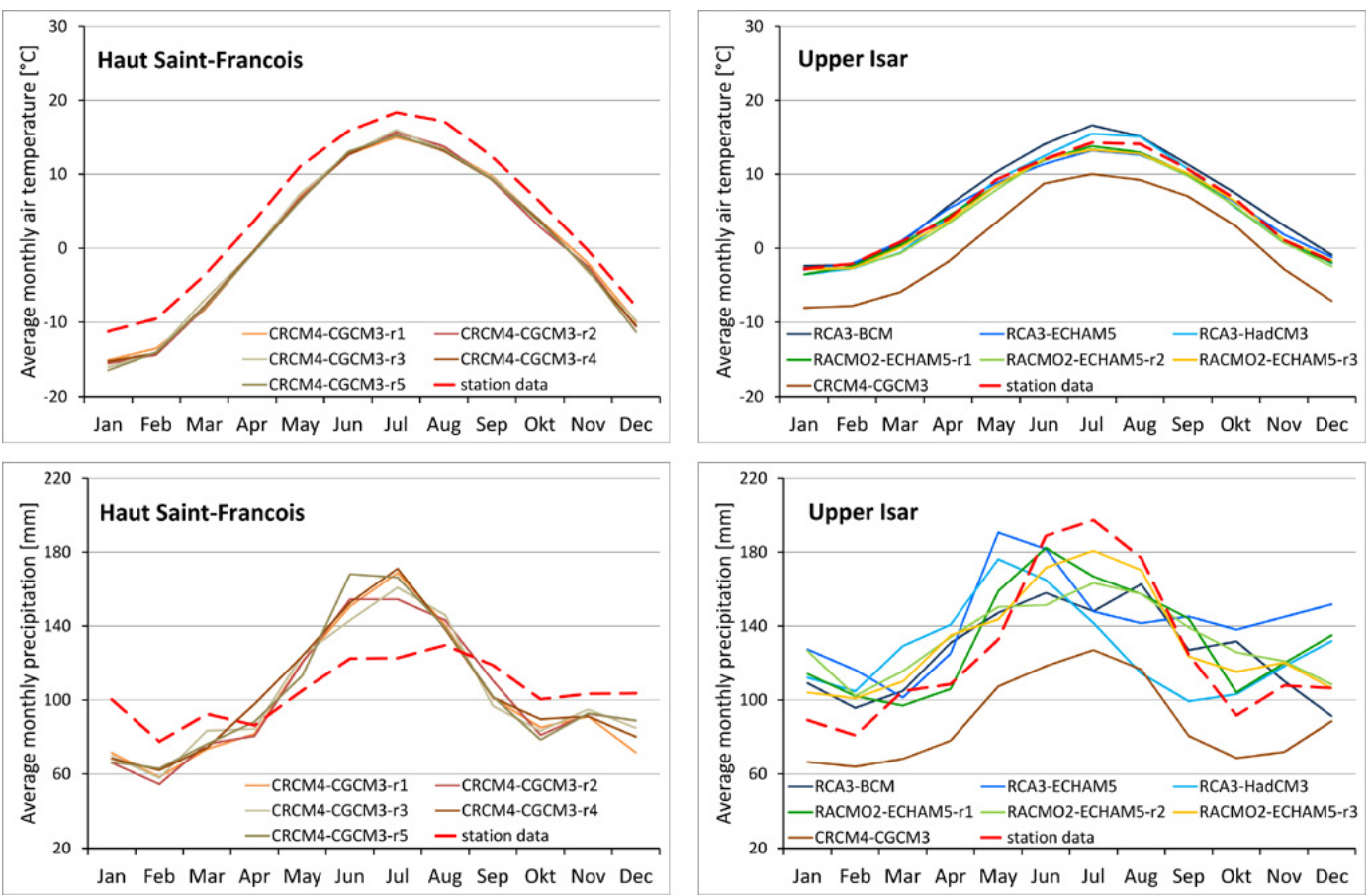

Fig. 3. Climatology of air temperature (upper panels) and precipitation (lower panels) over the main catchments Haut-Saint-François (left panels) and Upper Isar (right panels) derived from climate models and observations. (Acronyms refer to RCM-GCM combinations and runs in a GCM member ensemble.)

precipitation for each day in order to accommodate for a finer temporal resolution of the model data.

It should be noted that total precipitation is not forced to match the observation after bias correction using LOCI. Only the targeted statistics of the chosen method will fit the same statistics computed from the observations, this is an arbitrary choice. In cases where multiple members are available, a single set of bias correction parameters is computed from the statistics of the ensemble and then applied to each individual member in order to retain the modeled natural variability. In all other cases, there is one set of parameters per climate simulation.

In terms of climate change signal from the chosen RCMs for the 2050 horizon, the Haut-Saint-François region is projected to see its temperature increase by about $3^{\circ} \mathrm{C}$ with up to $4^{\circ} \mathrm{C}$ in winter. Precipitation is projected to increase by up to $30 \%$ in winter, about $20 \%$ in spring and fall and to decrease slightly during summer months. For the Upper Isar, a 1 to $3{ }^{\circ} \mathrm{C}$ increase in temperature is projected, with the larger uncertainty coming from the choice of multiple RCMs and driving GCMs. The precipitation change signal is mixed, showing a general increase in spring and a decrease in summer for all but the RCA-BCM simulation. Again, the various choices of atmospheric models introduce a rather large uncertainty of about $20 \%$ in the projected precipitation changes. It has to be noted that the depicted precipitation changes in Fig. 4 are based on uncorrected monthly values. As the LOCI method scales precipitation intensities, the bias corrected precipitation change signal is scaled accordingly with the exception of days with rainfall below the wet-day threshold. Also, it can already be seen that even with its large bias with respect to observations in the Upper Isar, the CRCM-CGCM model projected climate change is in line with the other models.

\subsection{The hydrological model ensemble}

The hydrological model (HyM) ensemble constructed for the QBic3 project is composed of four models: HSAMI (Fortin, 2000), HYDROTEL (Fortin et al., 2001), WASIM (Schulla and Jasper, 2007) and PROMET (Mauser and Bach, 2009). These models were calibrated with observed meteorological data and reflect different levels of structural complexity developed by the scientific community as discussed in more depth by Velázquez et al. (2013). These range from empirical, lumped runoff models to distributed, process-based land surface models. The structural complexity of the chosen hydrological models differs with regard to the characteristics (see Table 2):

1. The spatial resolution within the ensemble ranges from the lumped model HSAMI via the semi-distributed model HYDROTEL to the fully distributed $\left(1 \times 1 \mathrm{~km}^{2}\right)$ water budget and runoff models WASIM and PROMET.

2. The computation of evapotranspiration (ET) ranges from empirical estimates of the potential ET (that are 

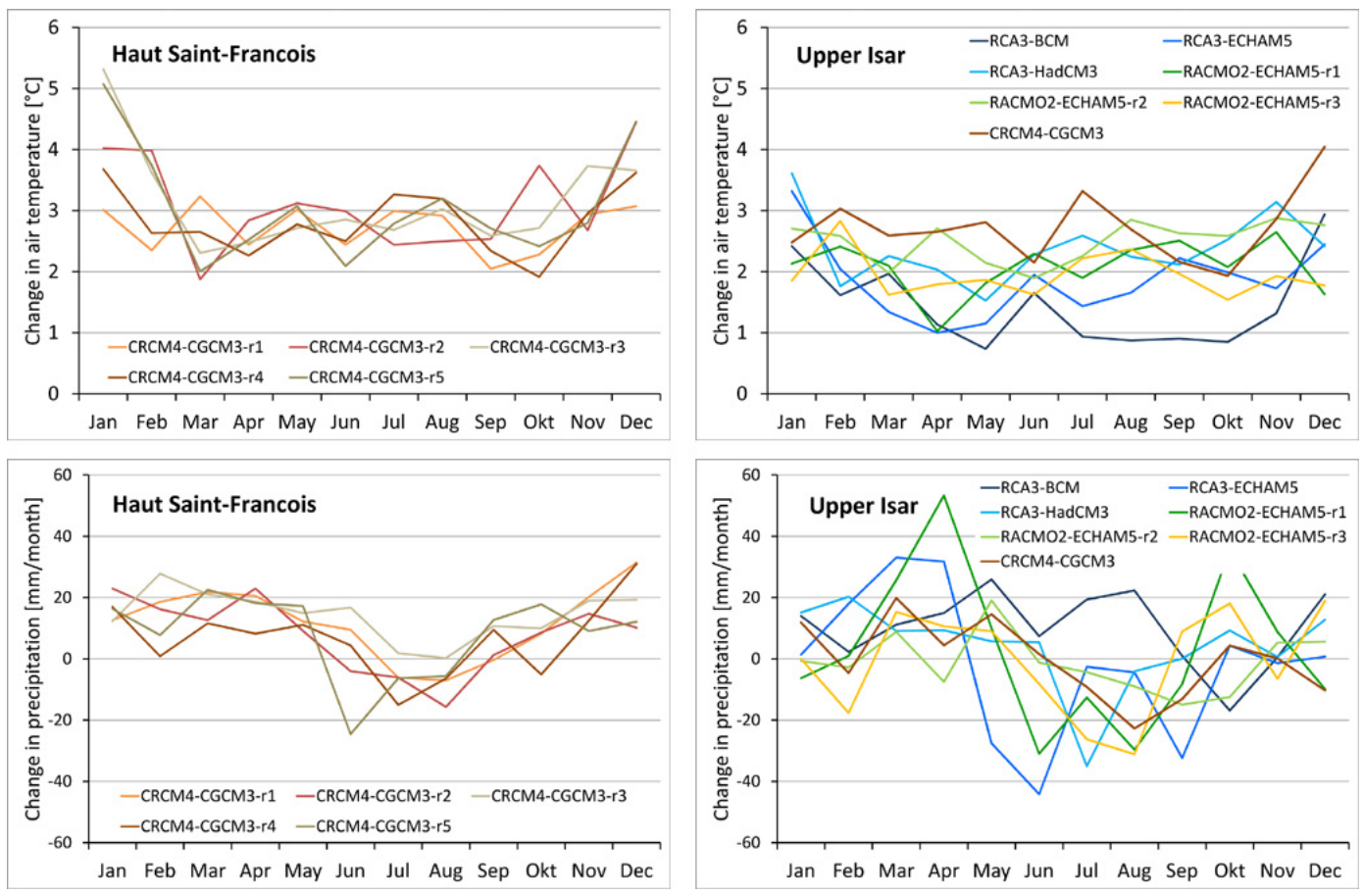

Fig. 4. Climate change signal of air temperature (upper panels) and precipitation (lower panels) over the two main catchments Haut-SaintFrançois (left panels) and Upper Isar (right panels) between the reference (1971-2000) and the future (2041-2070) period. (Acronyms refer to RCM-GCM combinations and runs in a GCM member ensemble.)

Table 2. Characteristics of the hydrological model ensemble.

\begin{tabular}{|c|c|c|c|c|}
\hline & HSAMI & HYDROTEL & WASIM-ETH & PROMET \\
\hline Model type & Conceptual & Mixed & Mixed & Process-based \\
\hline Resolution (temporal, spatial) & $24 \mathrm{~h}$, lumped & $\begin{array}{l}24 \mathrm{~h} \text {, HRUs (hy- } \\
\text { drological response } \\
\text { units) }\end{array}$ & $\begin{array}{l}24 \mathrm{~h}, \quad \text { fully dis- } \\
\text { tributed }\left(1 \times 1 \mathrm{~km}^{2}\right)\end{array}$ & $\begin{array}{l}1 \mathrm{~h}, \quad \text { fully dis- } \\
\text { tributed }\left(1 \times 1 \mathrm{~km}^{2}\right)\end{array}$ \\
\hline Meteorological inputs & \multicolumn{2}{|c|}{ Temperature, precipitation } & \multicolumn{2}{|c|}{$\begin{array}{l}\text { Temperature, precipitation, humidity, } \\
\text { wind speed, radiation }\end{array}$} \\
\hline Evapotranspiration (ET) & $\begin{array}{l}\text { Potential ET, em- } \\
\text { pirical } \\
2000)\end{array}$ & $\begin{array}{l}\text { Potential ET, Fortin } \\
\text { or Thornthwaite }\end{array}$ & $\begin{array}{l}\text { Potential ET, } \\
\text { Penman-Monteith }\end{array}$ & $\begin{array}{l}\text { Actual ET, } \\
\text { Penman-Monteith }\end{array}$ \\
\hline Soil water model & $\begin{array}{l}\text { Saturated \& unsat- } \\
\text { urated zone reser- } \\
\text { voirs }\end{array}$ & $\begin{array}{l}3 \text { soil layers, infil- } \\
\text { tration approach }\end{array}$ & $\begin{array}{l}\text { Multiple layers, } \\
\text { Richards' equation }\end{array}$ & $\begin{array}{l}4 \text { soil layers, Philip } \\
\text { equation }\end{array}$ \\
\hline Snow pack model & $\begin{array}{l}\text { Temperature-index } \\
\text { approach }\end{array}$ & $\begin{array}{l}\text { Temperature- } \\
\text { index incl. energy } \\
\text { balance }\end{array}$ & $\begin{array}{l}\text { Temperature-index } \\
\text { approach }\end{array}$ & $\begin{array}{l}\text { Snow pack energy } \\
\text { balance }\end{array}$ \\
\hline
\end{tabular}

reduced afterwards to fit runoff) to process-based algorithms of the actual ET. (a) PROMET has the most complex ET algorithm of this ensemble consisting of a soil-vegetation-atmosphere transfer (SVAT) scheme that describes the processes of and the resistances to water, energy and radiation transfer with physical and empirical parameters. These resistances are used in the Penman-Monteith formula for the calculation of the actual ET. (b) In WASIM, merely the potential ET is sim- ulated with the Penman-Monteith equation, which is, in a second step, reduced to actual ET as a function of the current soil matrix potential. (c) In HYDROTEL, potential ET is computed by an empirical formulation (Fortin, 2000) for Québec or by the Thornthwaite approach for the Bavarian region. Potential ET is then reduced to an actual value based on soil water availability. (d) HSAMI also estimates evapotranspiration with the 
empirical formulation of Fortin (2000) using minimum and maximum air temperature only.

3. The computation of the soil water balance differs strongly between models. Whereas in HYDROTEL a homogeneous distribution of properties over the soil column is assumed, the soil modules in WASIM and PROMET describe the soil column by different homogenous layers, which reflect the natural layer structure of soil horizons. HSAMI plainly uses two calibrated linear reservoirs to represent the saturated and unsaturated zones.

4. The computation of snow melt: Whereas HSAMI, HYDROTEL and WASIM use a simple temperature index approach for snow melt, PROMET calculates the radiation and temperature driven snow surface energy balance to compute the built-up and ablation of the snow water storage.

5. Moreover, because different algorithms of surface processes like snow melt and evapotranspiration are employed, the number of required meteorological input variables varies between models. While the more simple models run with daily values of air temperature and precipitation fields only, WASIM and PROMET additionally require wind speed, relative humidity and solar radiation fields.

Yet, when interpreting the effects of model structure on runoff results, multiple model characteristics have to be taken into account. For example, although the ET algorithm is an important characteristic for the simulation of the catchment water balance, its effect can only be assessed in combination with other model characteristics. Moreover, the actual simulated ET also depends on the spatial resolution of land surface properties and the available soil water content. Lumped models, which calculate the mean of the effect from all different land cover classes and soils within one subcatchment, introduce catchment specific correction factors to adjust the simulated runoff. In distributed models, parameters for land cover and soils describe the spatially distributed properties of the land surface. Furthermore, in complex models such as PROMET, projected future changes in ET or snow cover depend on multiple meteorological variables. For example, changes in relative humidity or solar radiation may counter or enhance hydrological change caused by changes in temperature or precipitation characteristics.

In climate change research, it is important to note that increasing realism does not guarantee an increase in HyM performance (the ability to reproduce hydrographs). Through the reduced need for calibration, increasing model complexity is expected to enhance the robustness of a model's representation of the runoff regime in a changed environment. Since climate change research assumes a significant drift of the climatic regime from the reference period to the future, robustness of parametric information is required. Yet, since physically based models are more demanding in computing capacity and in input data requirements, climate change research needs to optimize the tradeoff between complexity and robustness. Within QBic3, Velázquez et al. (2013) have already explored the added value of using complex models within the HyM ensemble used in this study.

\section{Results and discussion}

To compare the effect of bias correction with the uncertainty range introduced by climate and hydrological models and the natural variability of climate, two ensembles per catchment are constructed from the models presented before:

1. At Saumon four HyMs are combined with either the direct $(\mathrm{BC} 0)$ or bias corrected $(\mathrm{BC} 1)$ meteorological data sets of five members of CRCM driven by CGCM for 20 members per ensemble. (This ensemble allows the estimation of the natural variability of climate over southern Québec.)

2. At Schlehdorf four HyMs are combined with seven climate simulations (either $\mathrm{BC} 0$ or $\mathrm{BC} 1$ ) produced with five different combinations of regional and global climate models for 28 members per ensemble. (This ensemble allows estimation of the climate model uncertainty over southern Germany.)

In the following, the simulated runoff characteristics of these ensembles are investigated during the reference period 1971 to 2000 as well as the change signal of the flow indicators between the reference and the future (2041 to 2070) period.

\subsection{Does bias correction of atmospheric forcing provide a more consistent representation of river runoff?}

The performance of the hydro-climatic simulation ensembles is evaluated by their capacity to represent observed hydrology in a consistent way. This is done by comparing observed and simulated hydrographs (Fig. 5) or by evaluating hydrological indicators (Fig. 6). This section assesses how biases in our RCM simulations (Fig. 3) affect runoff results and if bias correction is able to provide a better representation of the observed hydrograph.

Figure 5 presents observed and simulated average monthly discharge values over the reference period. Observed discharges are represented by the red curve, while the simulation results of the hydro-climatic model chain are represented by the shaded envelope (minimum-maximum values). The impact of bias correction on simulated discharges can be seen by comparing Fig. 5a and b for Saumon and Fig. 5d and e for Schlehdorf. In both cases, the hydro-climatic ensemble produced with $\mathrm{BC} 1 \mathrm{RCM}$ data is closer to observed discharge than the $\mathrm{BC} 0$ ensemble. As presented in Fig. $5 \mathrm{c}$ and $\mathrm{f}$, the 

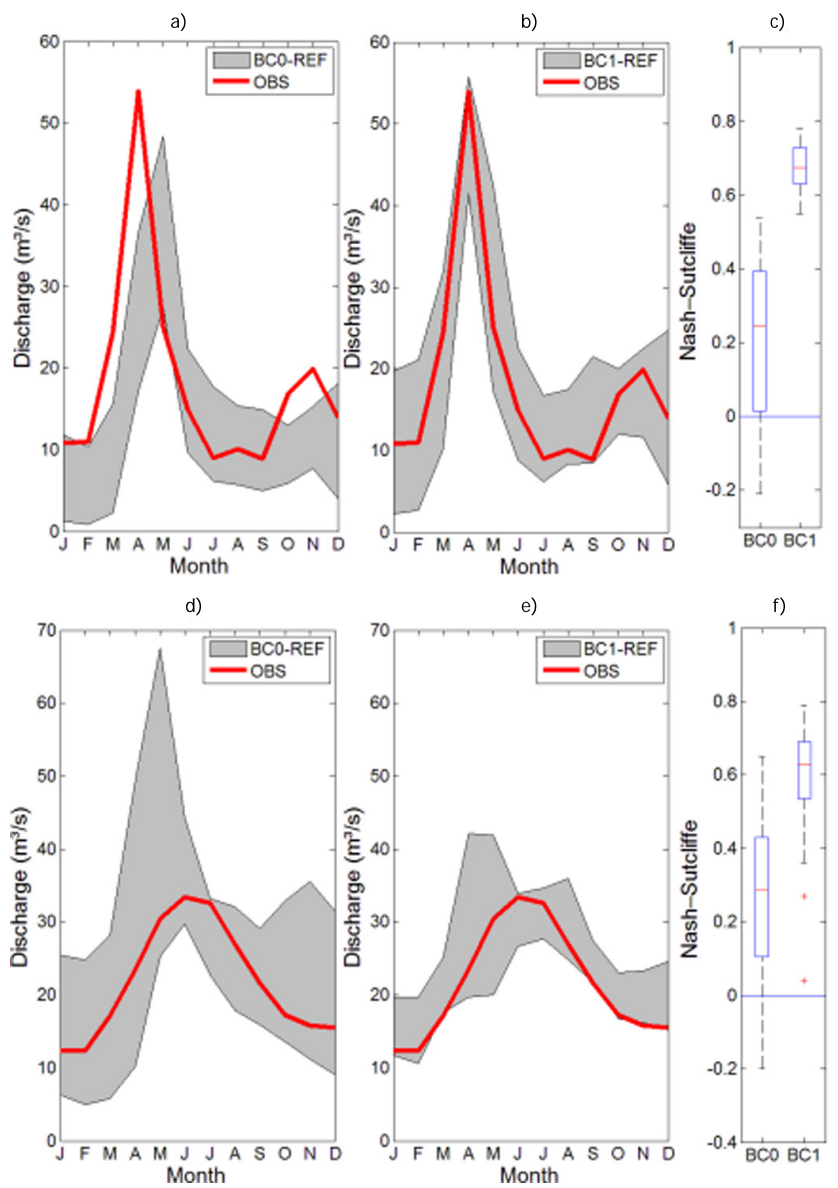

Fig. 5. Mean monthly observed discharge (red line) and the envelope of the ensemble simulations (1971-2000) with (a) BC0 for Saumon, (b) BC1 for Saumon, (d) BC0 for Schlehdorf, (e) BC1 for Schlehdorf. The box plots to the right (c and f) present NashSutcliffe model efficiency based on daily runoff.

evaluation of the Nash-Sutcliffe model efficiency confirms the overall better performance of $\mathrm{BC} 1$ values.

When looking at the details, one can observe that runoff at gauge Saumon is underestimated in winter if simulated with $\mathrm{BC} 0$ data. This could be related to the strong negative bias in simulated precipitation for these months (Fig. 3). The BC0 spring flood is shifted from April to May due to the cold bias in air temperature, which leads to a late melt of the snowpack. Moreover, the negative bias in precipitation leads to less snow storage and therefore to smaller spring floods for BC0 than observed. Similarly, the missing flood peak during autumn is due to the underestimation of rainfall in $\mathrm{BC} 0$. Bias correction generally increases simulated runoff during summer and autumn.

The investigation of the envelope of simulated runoff regimes produced with our five members of CRCM-CGCM reveals an interesting effect of bias correction on the spread of simulated mean monthly runoff values. As expected, the envelope of the $\mathrm{BC} 1$ ensemble is shifted towards higher val- ues due to higher annual precipitation sums $(+60 \mathrm{~mm})$. Yet, when looking at seasons, the spread of results, hence the uncertainty stemming from GCM members and HyMs, is smaller during spring in the $\mathrm{BC} 1$ case as compared to $\mathrm{BC} 0$ and is larger for $\mathrm{BC} 1$ during fall and especially winter. Apparently, the cold bias of CRCM results in too low winter runoff for all members of the $\mathrm{BC} 0$ ensemble, while plausible winter temperatures seem to produce more realistic, but also more variable flows in the $\mathrm{BC} 1$ case. By contrast, corrected winter precipitation sums and air temperatures result in a closer fit of the spring flood peak for $\mathrm{BC} 1$, while for $\mathrm{BC} 0$ the spring flood peak timing seems to occur between April and May depending on the simulation.

The Schlehdorf runoff regime based on $\mathrm{BC} 0$ has a huge spring flood peak that is related to a subset of the hydroclimatic ensemble that overestimates precipitation in winter and spring (Fig. 3). Especially the strong positive precipitation bias in May in most RCM simulations leads to a distinct, plausible decrease of the peak flow through bias correction. Yet, unlike in the Saumon case, the BC0 peak time is not shifted compared to $\mathrm{BC} 1$, because temperature biases are generally small. Runoff in fall and winter is also overestimated by the $\mathrm{BC} 0$ ensemble, especially at the end of the year, which is again related to precipitation biases (Fig. 3). Of course $\mathrm{BC} 1$ does clearly improve the results for Schlehdorf (Fig. 5), but a general overestimation of runoff remains. Thus, bias correction improves the situation significantly, but some artifacts seem to resist.

As expected, the envelope of the $\mathrm{BC} 1$ ensemble for Schlehdorf is distinctly smaller than the $\mathrm{BC} 0$ ensemble; hence it seems to be a more consistent ensemble with regard to simulated runoff. Especially the extremely large variability of BC0 simulated runoff peaks in spring, which is caused by some apparent outliers, is strongly reduced in the $\mathrm{BC} 1$ case. But also in fall and winter, bias correction results in a much smaller envelope and hence less variability between ensemble simulations, because both temperature and precipitation are corrected toward observed values. On average, fewer simulations overestimate runoff for Schlehdorf, because precipitation of the $\mathrm{BC} 1$ ensemble is $100 \mathrm{~mm}$ per year lower than in the $\mathrm{BC} 0$ ensemble.

Figure 6 presents the relative error of simulated indicators compared to observed MF, HF2 and 7LF2. One can notice that $\mathrm{BC} 1$ error values are in general smaller than $\mathrm{BC} 0$ errors. At Saumon, the combined MF uncertainty, related to natural variability of climate and the HyM ensemble (expressed by the width of a box, which indicates the quartiles of the ensemble), seems to be similar (around 10\%) for both cases. Yet, observing Nash-Sutcliffe model efficiency (Fig. 5) and the median of the relative MF error, one can note a significant restoration of simulation accuracy through bias correction. For 7LF2, bias correction does enhance the ensemble performance by clearly reducing both the spread of results and the average error. Yet, the same conclusion cannot be transposed to the relative $\mathrm{HF} 2$ error values. Although $\mathrm{BC} 1$ errors do not 

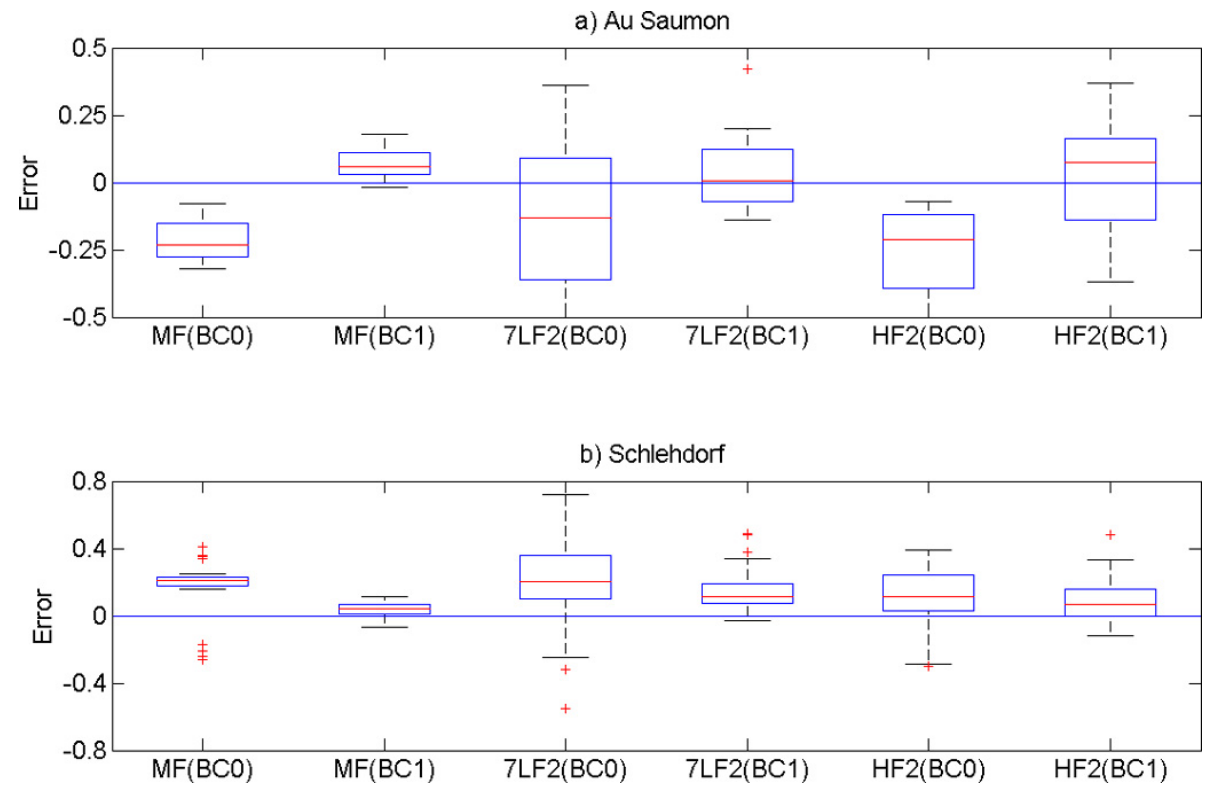

Fig. 6. Box plots of the relative errors of hydrological indicators simulated with either direct (BC0) or bias corrected (BC1) RCM drivers compared to indicators calculated from observed runoff (1971-2000).

suffer from an underestimation of high flows, the median and the spread of errors do not significantly improve when temperature and precipitation are corrected.

At gauge Schlehdorf, both the MF and 7LF2 indicators are greatly improved by bias correction. For both, $\mathrm{BC} 1$ results in a median closer to zero, less variability as expressed by the box plot and significantly less outliers as depicted by single data points. Of course this improvement is also reflected by the Nash-Sutcliffe model efficiency plots in Fig. 5f, although two relatively low model efficiencies remain in the $\mathrm{BC} 1$ case. Yet, regarding the relative deviation of simulated HF2 bias correction again does not improve model performance that well. Both $\mathrm{BC} 0$ and $\mathrm{BC} 1$ box plots are quite similar, which implies that both HyM structure and the intensity of singular events in RCM precipitation time series are of greater importance than average precipitation frequency and intensity.

In summary, bias correction improves the representation of simulated hydrological regimes. It reduces both the average and the maximum error of the simulated mean monthly or daily discharge. Bias correction also has a positive effect on the overall synchronism and seasonality of the hydrograph. Yet, its effect on the uncertainties within an ensemble is not clear, as those effects seem to be season, model and site specific. Furthermore, bias correction may affect different hydrological processes in different ways, and as those processes are intertwined in HyMs, runoff is sometimes affected in unpredictable ways. Our results also show that it has little impact on high-flow indicators, while the simulation of low flows seems to be especially sensitive to the use of bias correction.
Even if it ensures physical consistency between climate variables, the direct use of RCM output provides a disrupted representation of the hydrological regime for both Québec and Bavaria. The use of bias correction provides a more consistent representation of the hydrological regime, yet the consistency between climate variables is disrupted.

\subsection{What are the expected impacts of climate change and does bias correction affect indicator changes?}

Figure 7 presents the change in selected hydrological indicators between reference and future period for the au Saumon catchment, with a distinction based on whether bias correction was used or not. Significant change signals can be seen in the date of spring flood (earlier) and low-flow indicators (more severe in summer, less in winter). Overall mean flow tends towards a slight increase while the high-flow indicators offer a low signal to noise ratio.

The impact of bias correction appears to be minimal for most indicators. The most obvious difference occurs with the date of spring flood for which the distribution of results is shifted by 3 days. All hydrological simulations project an earlier spring flood, as shown in Fig. 7. The lags range between 8 and 20 days. This could be the consequence of an increase in temperature and precipitation projected by the climate model simulations for winter (Fig. 4), leading to faster snow melt and hence to a shift in peak runoff. However, the bias corrected simulations seem to project a shorter lag compared to the $\mathrm{BC} 0$ simulations. Figure 8 shows the results for Schlehdorf. The ensemble tends towards a small decrease in overall mean flow and an earlier date of spring flood. The low-flow indicators present two interesting 

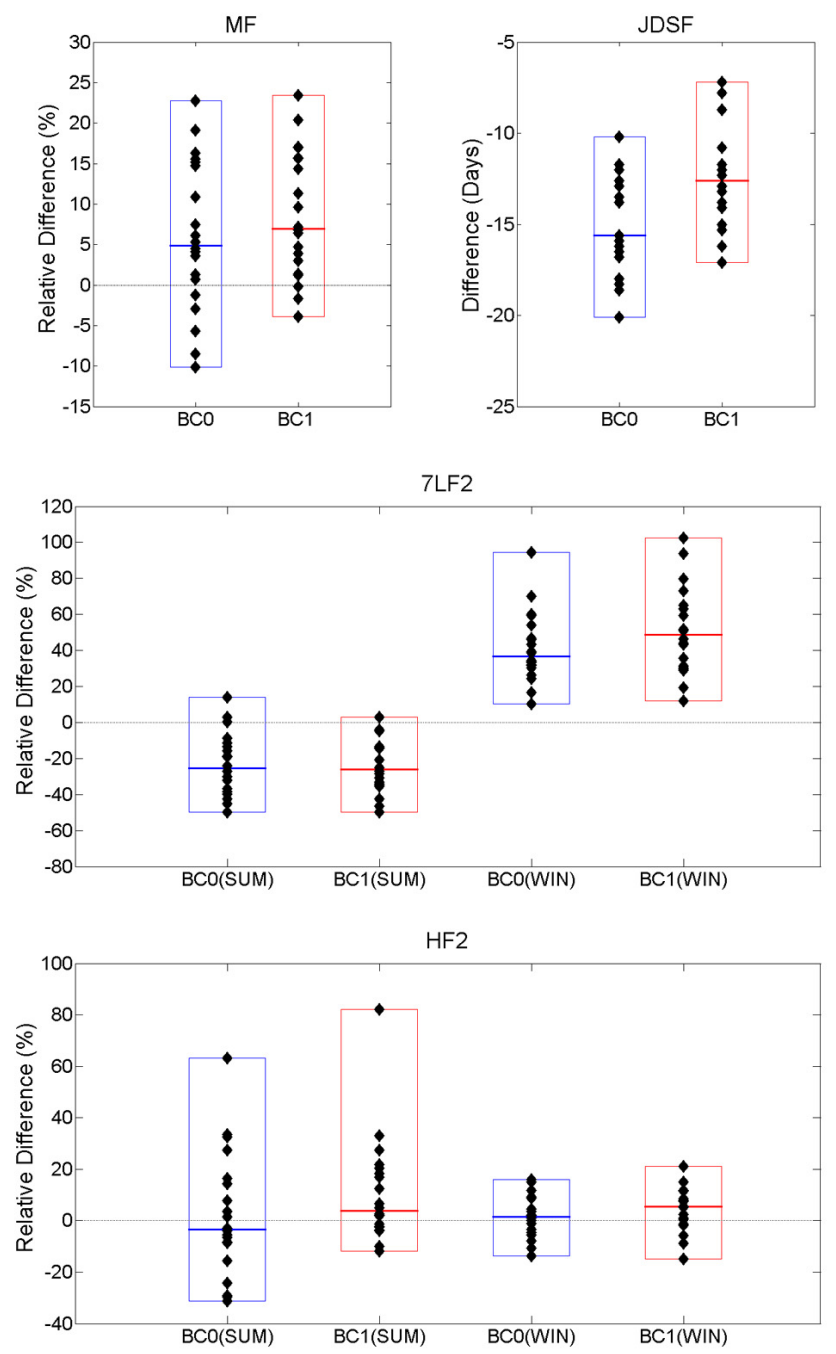

Fig. 7. Relative change of the investigated indicators between reference and future period at Saumon based on five members of the CRCM-CGCM ensemble over Québec.

cases highlighting different ways in which bias correction can impact the results. First, in summer, simulations using the CRCM project an increase in L7F2 ranging from $20 \%$ to $90 \%$. Bias correction modifies those projections to a range of $-20 \%$ to 0 . Since the CRCM simulation had the largest biases over this region, the role of bias correction on the ensemble appears to be one of outlier correction in this case. Second, in winter, the simulations using the CRCM once again shift from a projected increase to a projected decrease of L7F2 with bias correction. However, this highlights the importance of an ensemble projection, as the other two RCMs show a wide range of positive and negative signals both with and without bias correction. At last, the large amount of uncertainty in the ensemble results demonstrates that it is hard to reach a conclusion for the high-flow indicator.

Another observation is that, in general, the range of the ensemble is either maintained or reduced (sometimes signifi-
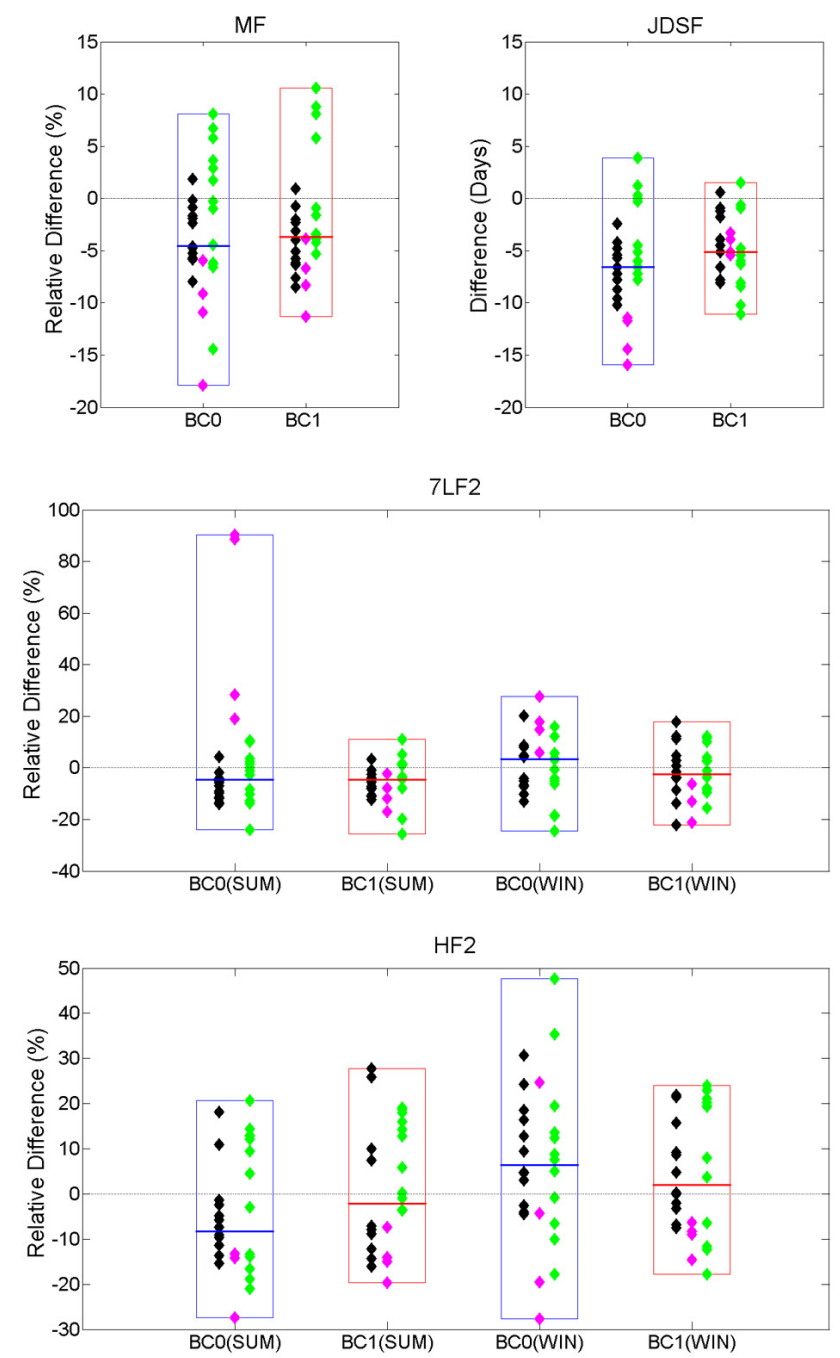

Fig. 8. Relative change of the indicators between reference and future period at Schlehdorf. The black dots indicate the RACMO simulations driven by ECHAM. Green dots specify RCA simulations driven by different pilots (BCM, ECHAM and HadCM); pink dots indicate the CRCM-CGCM simulations.

cantly, as is the case with winter high flows), suggesting that bias correction has a damping effect on the climate change uncertainty. Assuming that bias correction is valid, this is obvious as it is designed to bring the biased simulations back to "reality".

The rank-sum Wilcoxon test is used in order to compare the samples of climate change signals. The null hypothesis (H0) is that two investigated data samples (BC0 and $\mathrm{BC} 1$ ) have been drawn from the same distribution. In this study, the null hypothesis is tested at four significant levels, from $5 \%$ to $35 \%$.

Figure 9 shows the results of this statistical test for Saumon and Schlehdorf. In this figure, the blue square indicates no rejection of the null hypothesis, while a number in the square shows the threshold at which the null hypothesis was 


\begin{tabular}{|l|c|c|c|c|c|c|}
\hline Au Saumon & CRCM-CGCM 1 & CRCM-CGCM 2 & CRCM-CGCM 3 & CRCM-CGCM 4 & CRCM-CGCM 5 & All RCM runs \\
\hline MF & & & & & & $35 \%$ \\
\hline JDSF & $15 \%$ & $35 \%$ & $15 \%$ & $15 \%$ & $35 \%$ & $5 \%$ \\
\hline 7LF2 summer & & & & & & \\
\hline 7LF2 winter & & & & $25 \%$ & $25 \%$ & $35 \%$ \\
\hline HF2 summer & & $15 \%$ & & & & $15 \%$ \\
\hline HF2 winter & & $25 \%$ & $25 \%$ & & & \\
\hline
\end{tabular}

\begin{tabular}{|l|c|c|c|c|c|c|c|c|}
\hline \multicolumn{1}{|c|}{ Loisach } & $\begin{array}{c}\text { RACMO- } \\
\text { ECHAM 1 }\end{array}$ & $\begin{array}{c}\text { RACMO- } \\
\text { ECHAM 2 }\end{array}$ & $\begin{array}{c}\text { RACMO- } \\
\text { ECHAM 3 }\end{array}$ & RCA-BCM & RCA-ECHAM & RCA-HadCM & CRCM-CGCM & All RCM runs \\
\hline MF & & & $25 \%$ & $15 \%$ & $25 \%$ & & \\
\hline JDSF & & $5 \%$ & $15 \%$ & $5 \%$ & $35 \%$ & $25 \%$ & $5 \%$ & \\
\hline 7LF2 summer & $25 \%$ & & & $25 \%$ & & & $5 \%$ & \\
\hline 7LF2 winter & & & $35 \%$ & & $5 \%$ & & $15 \%$ & $3 \%$ \\
\hline HF2 summer & & & $35 \%$ & & $5 \%$ & $25 \%$ & $15 \%$ \\
\hline HF2 winter & & & & & & & \\
\hline
\end{tabular}

Fig. 9. Results of the Wilcoxon tests comparing BC0 with BC1 results for Saumon (au Saumon River) and Schlehdorf (Loisach River). Boxes show either the level of rejection $(5 \%, 15 \%, 25 \%, 35 \%)$ or no value if $\mathrm{H} 0$ was never rejected.

rejected. The lower the significance level at which the test is rejected, the stronger is the evidence that $\mathrm{BC} 0$ and $\mathrm{BC} 1$ do not come from the same distribution. In other words, it means that the bias correction has a significant impact on the climate change signal in hydrological indicators.

For Saumon, rejection of the null hypothesis is generally weak. The JDSF is the only indicator that is affected by bias correction for all members. When looking at all members together, the rejection is even stronger (this is an indication that the impact of bias correction on the change in JDSF of each member was in the same direction). Similar results are observed for MF and Summer HF2. The winter 7LF2 shows the opposite behavior, where some individual members reject the null hypothesis more strongly than the ensemble (the impact of bias correction on individual members is not consistent).

For Schlehdorf, the two most biased climate models (CRCM-CGCM and RCA-BCM) show the most rejection. The effect of using an ensemble of multiple climate models is clearly shown by the few rejections of the null hypothesis when indicators are analyzed based on all available RCM runs. Actually, while the null hypothesis for JDSF is usually rejected for individual models, there is no rejection at all for the ensemble.

Hence, while the climate change signals of outliers can be significantly modified by bias correction, it is recommended to present both results with and without bias correction in situations where only a few climate simulations are used. When multiple climate simulations are available, the described results suggest that the general climate change signal is less impacted and also supports the importance of ensemble projections for robust change signal projections.

\section{Conclusion}

A modeling chain has been constructed in order to simulate present-day and future runoff for the au Saumon (gauge Saumon) and Loisach (gauge Schlehdorf) catchments. Climate simulations chosen for this purpose often have biases making it difficult to reproduce observed hydrological conditions. For this reason, bias correction of climate model data is used in many projects, but this added procedure contributes to the overall uncertainty. In fact, each component of such a hydro-climatic modeling chain contributes to the overall uncertainty. There are choices to be made about which general circulation models, regional climate models and hydrological models are used, and whether natural variability is considered and/or bias correction is applied. Other sources of uncertainty that were not explicitly considered in this study include emission scenarios, statistical downscaling methods and variations in hydrological model calibration approaches.

The focus of this work is on the impact of the bias correction methods used in our study on simulated runoff characteristics and their climate change signals. At gauge Saumon, bias correction impacts are evaluated compared to the uncertainties introduced by natural variability and hydrological models, while at gauge Schlehdorf the evaluation is based on an ensemble of both climate and hydrological models. Although the uncertainties in (regional) climate simulations are well known (Foley, 2010) and are considered in up-todate investigations (Teutschbein et al., 2011), the uncertainty from hydrological models needs to be considered as well. Yet, it would be important to know which level of model complexity is necessary so that a given hydrological model reacts plausibly to future changes in climate, both in a qualitative and quantitative analysis. As this question is difficult 
to answer, our model ensemble covers the typical range of model complexities used in climate change impact studies, thus the range of results produced by these models shall give a good estimate of the uncertainty range regarding hydrological model complexity (Velázquez et al., 2013).

As expected, bias correction of regional climate simulations (before using them in hydrological models) systematically provides a closer to reality representation of the observed hydrograph and therefore of both mean and low-flow indicators. Yet, high-flow indicators seem to be less affected, because simulation of high flows is mainly determined by a hydrological model's structure and the simulated frequency of intense precipitation events. When it comes to the climate change signal, bias correction can have a significant impact on individual simulations, but its use on a large ensemble has a much smaller effect. In particular, the effect of bias correction on the change signal of hydrological indicators is larger for more strongly biased climate simulations, while the average signal of a large ensemble including those simulations is hardly affected. Yet, identifying outliers (biased simulations) is nontrivial. Whether a single climate simulation is an outlier because of climate model inherent biases, and not a plausible climatic scenario, must be carefully evaluated. So based on our results and in this large ensembles context, two viewpoints can be adopted:

1. Bias correction can be seen as mostly unnecessary to obtain the climate change signal of the investigated hydrological indicators, since other sources of uncertainty dominate.

2. Bias correction is safe to use in order to produce coherent present and future hydro-climatic scenarios for adaptation strategies, since it does not significantly alter the change signal of those indicators.

Our particular "large ensemble" for the Loisach catchment reveals a large uncertainty in the climate change signal of certain hydrological indicators, notably of high- and low-flow indicators, meaning that much remains to be done in improving the modeling chain to draw robust conclusions regarding those indicators.

Based on our results for two humid, snowmelt affected catchments, we assume that bias correction does not bring much added-value information to the analysis of relative changes in hydrological indicators when considering other sources of uncertainty, mainly the choice of climate and hydrological models. However, this methodology should be validated upon a wider set of catchments representing different runoff regimes (spatial validation) and a larger set of both climate simulations and bias correction methods to improve the robustness of this conclusion. Furthermore, we recommend the development of a bias correction method that aims at a fair trade-off between climate variables and hydrological regime consistency.
Acknowledgements. Financial support for this project has been provided by the PSR-SIIRI program of the Québec Ministry for Economic Development, Innovation and Export (MDEIE), as well as by the Bavarian State Ministry for Environment and Health (StMUG).

The CRCM4 data has been generated and supplied by the Ouranos Consortium, Montreal. Furthermore, we would like to thank Erik Kjellström (SMHI) and Erik van Meijgaard (KNMI) for their invaluable support in acquiring the data from their respective regional climate models, RCA3 and RACMO2. The authors also wish to thank S. Hagemann, U. Ehret and S. Schymanski for their helpful reviews of the manuscript.

Edited by: S. Schymanski

\section{References}

Andersson, L., Samuelsson, P., and Kjellström, E.: Assessment of climate change impact on water resources in the Pungwe river basin, Tellus A, 63, 138-157, doi:10.1111/j.16000870.2010.00480.x, 2011.

Bergstrom, S., Carlsson, B., Gardelin, M., Lindstrom, G., Pettersson, A., and Rummukainen, M.: Climate change impacts on runoff in Sweden-assessments by global climate models, dynamical downscaling and hydrological modelling, Climate Res., 16, 101-112, 2001.

Braun, M., Caya, D., Frigon, A., and Slivitzky, M.: Internal Variability of the Canadian RCM's Hydrological Variables at the Basin Scale in Quebec and Labrador, J. Hydrometeorol., 13, 443-462, doi:10.1175/jhm-d-11-051.1, 2011.

Caya, D. and Laprise, R.: A semi-implicit semi-Lagrangian regional climate model: The Canadian RCM, Mon. Weather Rev., 127, 341-362, 1999.

Chen, J., Brissette, F. P., and Leconte, R.: Uncertainty of downscaling method in quantifying the impact of climate change on hydrology, J. Hydrol., 401, 190-202, doi:10.1016/j.jhydrol.2011.02.020, 2011.

de Elía, R. and Côté, H.: Climate and climate change sensitivity to model configuration in the Canadian RCM over North America, Meteorologische Zeitschrift, 19, 325-339, doi:10.1127/09412948/2010/0469, 2010.

Déqué, M.: Frequency of precipitation and temperature extremes over France in an anthropogenic scenario: Model results and statistical correction according to observed values, Global Planet. Change, 57, 16-26, doi:10.1016/j.gloplacha.2006.11.030, 2007.

Déqué, M., Rowell, D., Lüthi, D., Giorgi, F., Christensen, J., Rockel, B., Jacob, D., Kjellström, E., de Castro, M., and van den Hurk, B.: An intercomparison of regional climate simulations for Europe: assessing uncertainties in model projections, Clim. Change, 81, 53-70, doi:10.1007/s10584-006-9228-x, 2007.

DVWK: Empfehlungen zur Berechnung der Hochwasserwahrscheinlichkeit, DVWK-Regeln, Hamburg, Berlin, 1979.

DVWK: Niedrigwasseranalyse Teil I: Statistische Untersuchung des Niedrigwasser-Abflusses, Verlag Paul Parey, Hamburg, Berlin, 1983.

Ehret, U., Zehe, E., Wulfmeyer, V., Warrach-Sagi, K., and Liebert, J.: HESS Opinions "Should we apply bias correction to global and regional climate model data?", Hydrol. Earth Syst. Sci., 16, 3391-3404, doi:10.5194/hess-16-3391-2012, 2012. 
Foley, A. M.: Uncertainty in regional climate modelling: A review, Prog. Physical Geogr., 34, 647-670, doi:10.1177/0309133310375654, 2010.

Fortin, V.: Le modèle météo-apport HSAMI: historique, théorie et application, Institut de recherche d'Hydro-Québec, Varennes, 68 pp., 2000.

Fortin, J. P., Turcotte, R., Massicotte, S., Moussa, R., Fitzback, J., and Villeneuve, J. P.: Distributed watershed model compatible with remote sensing and GIS data. I: Description of model, J. Hydrol. Eng., 6, 91-99, 2001.

Fowler, H. J., Blenkinsop, S., and Tebaldi, C.: Linking climate change modelling to impacts studies: recent advances in downscaling techniques for hydrological modelling, Int. J. Climatol., 27, 1547-1578, doi:10.1002/joc.1556, 2007.

Graham, L. P., Hagemann, S., Jaun, S., and Beniston, M.: On interpreting hydrological change from regional climate models, Clim. Change, 81, 97-122, 2007.

Haddeland, I., Heinke, J., Voß, F., Eisner, S., Chen, C., Hagemann, S., and Ludwig, F.: Effects of climate model radiation, humidity and wind estimates on hydrological simulations, Hydrol. Earth Syst. Sci., 16, 305-318, doi:10.5194/hess-16-305-2012, 2012.

Hagemann, S., Machenhauer, B., Jones, R., Christensen, O., Déqué, M., Jacob, D., and Vidale, P.: Evaluation of water and energy budgets in regional climate models applied over Europe, Clim. Dynam., 23, 547-567, 2004.

Hagemann, S., Chen, C., Haerter, J. O., Heinke, J., Gerten, D., and Piani, C.: Impact of a statistical bias correction on the projected hydrological changes obtained from three GCMs and two hydrology models, J. Hydrometeorol., 12, 556-578, 2011.

Hawkins, E. and Sutton, R.: The potential to narrow uncertainty in regional climate predictions, B. Am. Meteorol. Soc., 90, 10951107, 2009.

Horton, P., Schaefli, B., Mezghani, A., Hingray, B., and Musy, A.: Assessment of climate-change impacts on alpine discharge regimes with climate model uncertainty, Hydrol. Processes, 20, 2091-2109, doi:10.1002/hyp.6197, 2006.

Kjellström, E., Nikulin, G., Hansson, U. L. F., Strandberg, G., and Ullerstig, A.: 21st century changes in the European climate: uncertainties derived from an ensemble of regional climate model simulations, Tellus A, 63, 24-40, doi:10.1111/j.16000870.2010.00475.x, 2011.

Kleinn, J., Frei, C., Gurtz, J., Lüthi, D., Vidale, P., and Schär, C.: Hydrologic simulations in the Rhine basin driven by a regional climate model, J. Geophys. Res., 110, D04102, doi:10.1029/2004JD005143, 2005.

Liston, G. E. and Elder, K.: A meteorological distribution system for high-resolution terrestrial modeling (MicroMet), J. Hydrometeorol., 7, 217-234, 2006.

Maraun, D., Wetterhall, F., Ireson, A. M., Chandler, R. E., Kendon, E. J., Widmann, M., Brienen, S., Rust, H. W., Sauter, T., Themeß1, M., Venema, V. K. C., Chun, K. P., Goodess, C. M., Jones, R. G., Onof, C., Vrac, M., and Thiele-Eich, I.: Precipitation downscaling under climate change: Recent developments to bridge the gap between dynamical models and the end user, Rev. Geophys., 48, RG3003, doi:10.1029/2009rg000314, 2010.

Marke, T.: Development and Application of a Model Interface To couple Land Surface Models with Regional Climate Models For Climate Change Risk Assessment In the Upper Danube Watershed, Fakultät für Geowissenschaften, Ludwig-Maximilians-
Universität, München, 2008.

Mauser, W. and Bach, H.: PROMET - Large scale distributed hydrological modelling to study the impact of climate change on the water flows of mountain watersheds, J. Hydrol., 376, 362377, doi:10.1016/j.jhydrol.2009.07.046, 2009.

Minville, M., Brissette, F., Krau, S., and Leconte, R.: Adaptation to Climate Change in the Management of a Canadian WaterResources System Exploited for Hydropower, Water Resour. Manag., 23, 2965-2986, doi:10.1007/s11269-009-9418-1, 2009.

Music, B. and Caya, D.: Evaluation of the hydrological cycle over the Mississippi River basin as simulated by the Canadian Regional Climate Model (CRCM), J. Hydrometeorol., 8, 969-988, 2007.

Music, B. and Caya, D.: Investigation of the Sensitivity of Water Cycle Components Simulated by the Canadian Regional Climate Model to the Land Surface Parameterization, the Lateral Boundary Data, and the Internal Variability, J. Hydrometeorol., 10, 3 21, 2009.

Samuelsson, P., Jones, C. G., Willen, U., Ullerstig, A., Gollvik, S., Hansson, U., Jansson, C., Kjellström, E., Nikulin, G., and Wyser, K.: The Rossby Centre Regional Climate model RCA3: model description and performance, Tellus A, 63, 4-23, doi:10.1111/j.1600-0870.2010.00478.x, 2011.

Schmidli, J., Frei, C., and Vidale, P. L.: Downscaling from GCM precipitation: a benchmark for dynamical and statistical downscaling methods, Int. J. Climatol., 26, 679-689, doi:10.1002/joc.1287, 2006.

Schulla, J. and Jasper, K.: Model Description WaSiM-ETH, Institute for Atmospheric and Climate Science, Swiss Federal Institute of Technology, Zürich, 2007.

Teutschbein, C. and Seibert, J.: Regional Climate Models for Hydrological Impact Studies at the Catchment Scale: A Review of Recent Modeling Strategies, Geography Compass, 4, 834-860, doi:10.1111/j.1749-8198.2010.00357.x, 2010.

Teutschbein, C., Wetterhall, F., and Seibert, J.: Evaluation of different downscaling techniques for hydrological climate-change impact studies at the catchment scale, Clim. Dynam., 37, 20872105, doi:10.1007/s00382-010-0979-8, 2011.

Themeß1, M. J., Gobiet, A., and Leuprecht, A.: Empirical-statistical downscaling and error correction of daily precipitation from regional climate models, Int. J. Climatol., 31, 1530-1544, doi:10.1002/joc.2168, 2011.

van den Hurk, B., Hirschi, M., Schär, C., Lenderink, G., van Meijgaard, E., van Ulden, A., Rockel, B., Hagemann, S., Graham, P., and Kjellström, E.: Soil control on runoff response to climate change in regional climate model simulations, J. Climate, 18, 3536-3551, 2005.

van Meijgaard, E.: The KNMI regional atmospheric climate model RACMO version 2.1, Koninklijk Nederlands Meteorologisch Instituut, 2008

Velázquez, J. A., Schmid, J., Ricard, S., Muerth, M. J., Gauvin StDenis, B., Minville, M., Chaumont, D., Caya, D., Ludwig, R., and Turcotte, R.: An ensemble approach to assess hydrological models' contribution to uncertainties in the analysis of climate change impact on water resources, Hydrol. Earth Syst. Sci., 17, 565-578, doi:10.5194/hess-17-565-2013, 2013.

Wilby, R. L., Hay, L. E., Gutowski Jr., W. J., Arritt, R. W., Takle, E. S., Pan, Z., Leavesley, G. H., and Clark, M. P.: Hydrological responses to dynamically and statistically downscaled 
climate model output, Geophys. Res. Lett., 27, 1199-1202, doi:10.1029/1999g1006078, 2000.

Wilcoxon, F.: Individual Comparisons by Ranking Methods, Biometrics Bulletin, 1, 80-83, 1945.

Wood, A. W., Leung, L. R., Sridhar, V., and Lettenmaier, D.: Hydrologic implications of dynamical and statistical approaches to downscaling climate model outputs, Clim. Change, 62, 189-216, 2004.
Zabel, F., Mauser, W., Marke, T., Pfeiffer, A., Zängl, G., and Wastl, C.: Inter-comparison of two land-surface models applied at different scales and their feedbacks while coupled with a regional climate model, Hydrol. Earth Syst. Sci., 16, 1017-1031, doi:10.5194/hess-16-1017-2012, 2012. 